\title{
Editorial 34
}

\author{
Eric R. Scerri
}

Published online: 24 March 2010

(C) The Author(s) 2010. This article is published with open access at Springerlink.com

The first issue for this year is a special issue on the periodic table, which has been partly compiled by Professor Michael Laing of the University of Kwazulu in Natal, South Africa. Over the years Laing has written many thought provoking articles on the periodic table and various other fundamental issues in chemical education.

To readers who may be wondering why there seem to be so many articles on the periodic table in this journal I would like to pause to offer my opinion. There is little doubt that the study of the periodic table brings together many of the themes that interest philosophers of chemistry. First is the question of reduction, which is made more specific by asking whether the periodic table reduces to quantum mechanics. A related question is whether the periodic table is primarily a classification of the macroscopic elements, their atoms or both, and if the latter how the two levels of description mesh together.

Moreover it is becoming increasingly clear that the development of the periodic table and subsequent discoveries that it spawned represent something of a scientific revolution or at the very least the establishment of a new paradigm for chemistry. Revolutions in chemistry are few and far between. If we seek a revolution in the literal sense of a sudden change of the kind that Kuhn supposed, then one is led to the chemical revolution of Lavoisier. But if we look to new paradigms that may have developed more gradually and that set the theoretical as well as experimental agenda, and continue to do so, then the development of the periodic table provides a perfect example.

Let me turn to another point. The discovery of the periodic table shows many parallels with Darwin's discovery of the evolution of species by natural selection. Some of these parallels may be merely coincidental, such as the fact that Darwin ${ }^{1}$ published his monumental book in 1859, while Mendeleev's periodic system was published in 1869. Other parallels are more significant. In both cases the discovery set the agenda, the framework or

\footnotetext{
${ }^{1}$ Darwin delayed publication for about 30 years because of the controversial nature of his discovery. Another curious analogy, though also coincidental, is the fact that in 1858 Darwin's work was foreshadowed by that of Wallace, while Mendeleev's was foreshadowed in 1868 by the table of Lothar Meyer.
}

E. R. Scerri $(\bowtie)$

Department of Chemistry \& Biochemistry, UCLA, 607 Charles Young Drive East,

Los Angeles, CA 90095, USA

e-mail: scerri@chem.ucla.edu 
paradigm for research in the field, which persist to the present time. Darwin provided a natural classification of biological species, while Mendeleev provided a natural classification of the elements. In both cases the system of classification was eventually explained by a microscopic account and the attempts to do so produced fundamental discoveries in chemistry and biology. In the case of the periodic system motivated the discoveries of atomic structure, Bohr's quantum theory and eventually quantum mechanics. In the case of Darwin's theory it was genetics, genes and eventually the structure of DNA and all the technologies that have been made possible as a result.

In philosophy of biology Darwin's theory has rightly been at the heart of much research in the field. In the case of philosophy of chemistry, the central role of the periodic table has yet to be fully appreciated. Of course there are not the same social and theological implications in the case of the periodic table but the parallels between the two scientific developments remain undeniable.

Let me now turn to the papers in this issue. We begin with an intriguing article by the polymath Philip Stewart who is well known for having developed and championed his galaxy shaped periodic table. In his article Stewart examines the work of another polymath, Charles Janet, a French engineer who was responsible for devising the first versions of the left-step periodic table that continues to receive much attention from those interested in the foundations of the periodic table. The left-step table, or at least the best version of it, places the s-block elements to the right of the p-block to give an overall regular shape and has the controversial feature of placing helium among the alkaline earths. According to some authors the left-step table is more consistent with the quantum mechanical account of the periodic system. ${ }^{2}$ This is the view that I took in my book on the periodic system before becoming persuaded of another form that does not place the element helium among the alkaline earths of which I will say more at the end of this editorial.

This is followed by a piece on the Platinum group metals by Bill Griffith from Imperial College in London. These elements were all formerly placed a single group in the periodic table even though they form a three column wide block. They also consist of many of the metals that Mendeleev originally designated as transition metals in a sense that differs from the current meaning of the term.

For Mendeleev the transition metals were those that interrupted the sequence of increasing maximum oxidation states that one encounters on moving across the short-form periodic table. Whereas Mendeleev placed manganese in the same column as the halogens, he dealt with the next three elements and their homologues by 'dumping' them outside the main body of the periodic table. The first row of these elements consisted of iron, cobalt and nickel and below them were housed the platinum group metals of ruthenium, rhodium, palladium, osmium, iridium and platinum. Returning to the first row of these elements, nickel is followed by copper and zinc, which Mendeleev placed among the alkali metals and alkali earths, respectively because of their oxidation states.

This dumping ground of elements represented group 8 for Mendeleev, which coincidentally meant that the short form table possessed eight columns or groups even before any of the noble gases had been discovered. The article by Griffith focuses especially on the atomic weights of the platinum group members and the way in which they were included into the periodic system by the various discoverers of the periodic system.

Fathi Habashi's paper represents an interesting addition to the recurring discussions concerning the numbering of groups in the periodic table. By drawing on a lifetime of experience in metallurgy, Habashi suggests abandoning the numbering system altogether,

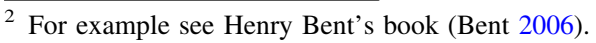


in favor of a new classification of elements into categories like "typical", "less typical", and "transition" elements. While doing this he makes a good case for distinguishing the elements in groups 11-13 inclusive (IUPAC numbering) from the remaining transition elements. Another original suggestion by Habashi concerns the placement of the element aluminum, which he argues should be positioned above scandium for a number of reasons.

Michael Laing's contribution is drawn from Oliver Sacks' delightful book, Uncle Tungsten. In it Sacks describes his boyhood and continuing fascination with chemistry and especially the periodic table. More specifically, Sacks describes how he was in the habit of plotting all forms of data for the elements onto graphs. This had the effect of both confirming the power of the periodic law to him and also raising a doubt in his mind concerning the placement of the last few elements that were known at the time, namely actinium, thorium, protactinium and uranium. Rather interestingly the young Oliver Sacks seems to have anticipated the repositioning of these elements to form a second series of rare earth elements, a step that was first taken by Glen Seaborg. ${ }^{3}$

The Marks brothers from New Zealand, luckily not spelled Marx, briefly criticize the IUPAC numbering system consisting of groups 1 to 18 and go on to propose a novel periodic table which they claim more faithfully reflects the chemical properties of the elements. Their table gives precedence to valences and bears some similarities to that of James Rota from Edmonton in Canada (Meta-synthesis website). The net outcome of the Marks table is the presence of fourteen groups numbered I to XIV in which the f-block elements are incorporated into the main body of the table.

Finally a paper by me, in which I attempt to lend some support for my recent claim that the placement of difficult elements like $\mathrm{H}, \mathrm{He}, \mathrm{Lu}, \mathrm{Lr}, \mathrm{Ac}$ and $\mathrm{La}$ can be settled by appealing to atomic number triads (Scerri 2008). The support I appeal to comes from the work of Danial Bonchev et al. who use information theory in a way that suggests that electronic configurations are correlated with, and perhaps even governed, by nuclear structure. Let me end by mentioning that our annual international conference will be held at University College, Oxford from the 9th to the 11th of August, 2010. Please see the ISPC website for details.

Open Access This article is distributed under the terms of the Creative Commons Attribution Noncommercial License which permits any noncommercial use, distribution, and reproduction in any medium, provided the original author(s) and source are credited.

\section{References}

Bent, H.: New Ideas in Chemistry from Fresh Energy for the Periodic Law. Author House, Bloomington, IN (2006).

Mazurs, E.G.: Graphic Representations of the Periodic System During One Hundred Years. University of Alabama Press, Tuscaloosa, Alabama (1974).

Meta-synthesis website. http://www.meta-synthesis.com/webbook/35_pt/pt_database.php?Button=post-2000 +Formulations.

Scerri, E.R.: The role of triads in the evolution of the periodic system. J. Chem. Educ. 85, 585-589 (2008). van Spronsen, J.W.: The Periodic System of Chemical Elements, A History of the First Hundred Years. Elsevier, Amsterdam (1969).

\footnotetext{
${ }^{3}$ Many other periodic tables from earlier times also suggest a second series in this way. Seaborg was by no means the first to arrive at this idea (Mazurs 1974; van Spronsen 1969).
} 